BAÍA DE GUANABARA: EDUCAÇÃO AMBIENTAL POR MEIO DE UMA TEMÁTICA INTERDISCIPLINAR

\title{
GUANABARA BAY: ENVIRONMENTAL EDUCATION THROUGH AN INTERDISCIPLINARY THEMATIC
}

\author{
DE SOUZA, Paulo Sérgio Alves ${ }^{1}$; RUA, Emílio Reguera² \\ 1,2 Ministério da Defesa, Fundação Osório, Rua Paula Ramos, 52, cep 20260-210, Rio de Janeiro - RJ, Brasil \\ e-mail: paulosasouza@gmail.com; emilio.rua@ig.com.br
}

\section{RESUMO}

Este trabalho apresenta o relato de um projeto interdisciplinar envolvendo as disciplinas Química e Estudos Regionais (disciplina do curso Técnico em Administração de Empresas). A Baía de Guanabara foi o pano de fundo para que os alunos, a partir da realidade de um ecossistema ambientalmente degradado, discutissem as causas e possíveis soluções de curto, médio e longo prazos para o equacionamento do problema. Esta abordagem permitiu, através do diálogo entre conceitos das duas disciplinas, a difusão da educação ambiental entre os alunos, bem como o desenvolvimento de uma sensibilidade socioambiental, indispensável a um futuro técnico em administração de empresas.

Palavras-chave: Educação Ambiental, Contextualização, Interdisciplinaridade.

\begin{abstract}
This paper shows an interdisciplinary project that involved two scholar subjects: Chemistry and Regional Studies (subject of business administration course of Fundação Osório). The Guanabara Bay was the scene for observations and discussions about the origins, causes and possible solutions in terms of time scale for the environmental question. This approach allowed, beyond the dialog between Chemistry and Regional Studies, the diffusion of environmental education and developed the social and environmental sensibility, terms so importants to improve a future professional in business administration.
\end{abstract}

Keywords: Environmental Education, Contextualization, Interdisciplinarity. 


\section{Introdução}

Com a intenção de satisfazer suas necessidades, o homem aumenta sua capacidade de intervir na natureza, surgindo conflitos e tensões com relação ao uso do espaço e dos recursos em função da tecnologia disponível. Isto porque, um dos aspectos mais graves da economia industrial é a pressão destrutiva que ele exerce sobre os recursos naturais, que são a base material sobre a qual se estabelece a vida humana.

Cabe aqui dizer que, a separação homem-natureza é uma característica que domina a sociedade capitalista, onde este sentimento de separação e dominação das sociedades humanas para com a natureza reflete-se, também, na exacerbação do individualismo em nossa sociedade.

A humanidade vai assumindo uma consciência individual com o passar do tempo. Cada vez mais deixa de se sentir integrada com o todo e de assumir a noção de parte da natureza. O ser humano se afasta da natureza nas sociedades atuais, não percebendo as relações de equilíbrio da natureza. Atua de forma totalmente desarmônica sobre 0 ambiente, causando grandes desequilíbrios ambientais. (Guimarães, 1995).

É a partir, principalmente, da década de 1960 que foi intensificada a percepção de que a humanidade pode caminhar aceleradamente para o esgotamento ou a inviabilização de recursos indispensáveis à sua própria sobrevivência. Gonçalves (1998), confirma esta preocupação quando diz que nossa sociedade está destruindo as fontes vitais à sua própria sobrevivência e que existe a possibilidade de reversão dessa tendência eco-suicida enquanto há tempo. Para tanto, é necessário desenvolver outras formas de relação com a extensão de nosso corpo que é a natureza, o que implica a adoção de outras técnicas e de outras relações entre os homens, ou seja, o desenvolvimento de outra cultura.

A constatação de que o avanço tecnológico tem sido associado à degradação do meio ambiente faz crescer 0 interesse mundial pela Educação Ambiental (EA), tentando resgatar a participação dos cidadãos na solução dos problemas ambientais, já que o futuro da humanidade depende da relação estabelecida entre a natureza e o uso pelo homem dos recursos naturais disponíveis.

$\mathrm{Na}$ Conferência das Nações Unidas para o Meio Ambiente Humano, realizada em Estocolmo, em 1972, definiu-se, pela primeira vez, a importância das ações educativas nas questões ambientais, o que gerou o primeiro "Programa Internacional de Educação ambiental", obtendo consolidação em 1975 pela Conferência de Belgrado.

Em 1977, na Conferência Intergovernamental de Educação Ambiental ocorrida em Tbilisi (Geórgia) foi produzido um documento que buscou traçar princípios, objetivos e metodologias para a EA, tornando-se um referencial para aqueles que procuram um embasamento teórico para as suas práticas educativas. Dentre outros princípios estabelecidos por este documento, destacam-se os que preconizam que a EA deve adotar uma perspectiva interdisciplinar, além de fazer com que os alunos participem da organização de suas próprias experiências de aprendizagem e que tenham a oportunidade de tomar decisões.

Em 1992, no Rio de Janeiro, foi realizada a Conferência das Nações Unidas sobre o Meio Ambiente e Desenvolvimento (Rio 92), onde diversas Organizações da Sociedade Civil elaboraram um tratado de Educação Ambiental para Sociedades Sustentáveis e Responsabilidade Global, em que reconhece a educação como um processo dinâmico e em permanente construção, propiciando a reflexão, o debate e a autotransformação das pessoas

Caracteriza-se, então, a EA como um processo permanente no qual os indivíduos a comunidade tomam consciência do seu meio ambiente e adquirem conhecimentos, valores, habilidades, experiências e determinação que os tornem aptos a agir e resolver problemas ambientais, presentes e futuros (Dias, 2000).

Percebe-se que a EA já é uma realidade e que políticas públicas já estão sendo tratadas para esta questão. A Constituição da República Federativa do Brasil de 1988 no seu artigo 225, é muito clara quando preconiza que: "Todos têm direito ao meio ambiente ecologicamente equilibrado, bem de uso comum do povo e essencial à sadia qualidade de vida, (...) cabendo ao Poder Público promover a Educação Ambiental em todos os níveis de ensino e a conscientização pública para a preservação do meio ambiente".

$$
\text { Esta abertura dada à EA pela }
$$


Constituição Federal vem favorecendo a sua institucionalização perante a sociedade brasileira. Desta forma, em meados da década de 1990, o Ministério da Educação e do Desporto (MEC) elaborou os Parâmetros Curriculares Nacionais (PCNs) em que o tema Meio Ambiente permeia todo o currículo, sendo tratado de forma articulada entre as diversas áreas do conhecimento, criando uma visão global e abrangente da questão ambiental.

A EA como eixo transversal no projeto político pedagógico pode contribuir para que se contemplem ações coletivas que resultarão na elaboração de uma proposta partilhada entre diferentes disciplinas escolares. Imprimir olhares e reflexões sob diferentes matizes contribui de forma decisiva para as discussões de EA, de química e de estudos regionais. Segundo Loureiro (2004), a categoria educar não se esgota em processos individuais e transpessoais. Engloba tais esferas, mas vincula-as às práticas coletivas, cotidianas e comunitárias que nos dão sentido de pertencimento à sociedade.

Aproveitar situações de impactos ambientais visando 0 processo ensinoaprendizagem dinâmico, interdisciplinar e contextualizado pode ser um modo de o professor despertar nos alunos a consciência da importância da química (e também de estudos regionais - adendo nosso) e levá-los a construir conceitos significativos para a melhoria de sua qualidade de vida, independente da situação sócio-econômica. (Vaitsman, E. P. e Vaitsman, D. S., 2006).

Ao se depararem situações próximas de suas realidades, os educandos procurarão atribuir sentido àquilo que estão vivenciando, utilizando-se dos conceitos disciplinares, de forma que, ao tentarem atribuir sentido ao que estão aprendendo, irão formular suas próprias "respostas", suas próprias maneiras de articular aquilo que está sendo ensinado com o que já "sabiam". Os educandos vão incorporar os discursos e as visões de mundo que circularam durante as atividades propostas, as aulas do professor, a discussão com os colegas, as leituras, etc. (Machado, A. H. e Mortimer, E. F., 2007).

Este trabalho buscou mostrar ao
educando que os estudos ambientais
transbordam limites disciplinares. Acrescente-se
a isso o fato de que a região de estudo - a Baía
de Guanabara - é resultado de um processo
histórico e de um modelo de desenvolvimento

que dilapidou o meio ambiente. O aluno foi desafiado a propor soluções de curto, médio e longo prazo para o desafio ambiental que se colocou.

Dentro do objetivo geral ressaltado anteriormente, esperava-se ainda sensibilizar as gerações futuras para os limites e possibilidades colocados por práticas preservacionistas e conservacionistas.

\section{Desenvolvimento}

O presente projeto realizou-se ao longo do segundo semestre de 2007 junto às duas turmas de terceiro ano do ensino médio do curso técnico de Administração de Empresas de uma escola federal da cidade do Rio de Janeiro e contou com duas etapas: a primeira no $3^{\circ}$ bimestre e a segunda no $4^{\circ}$ bimestre do corrente ano. Para tanto, foram eleitos alguns temas transversais que versassem sobre a realidade sócio-ambiental da Baía de Guanabara, a saber: Desenvolvimento Econômico; Balneabilidade e Qualidade das Águas; Atividade Pesqueira; Lixo Urbano e Reciclagem; Transportes.

Apresentaremos, a seguir, a descrição das etapas do projeto. Segue-se, também, uma explanação sobre o papel da construção do weblog enquanto elemento de mediação didática e divulgação do projeto de pesquisa e da relevância da realização do trabalho de campo.

\section{Terceiro Bimestre}

Os alunos de cada turma foram divididos em cinco grupos temáticos e receberam algumas orientações gerais e específicas.

Dentro de cada tema proposto, os alunos desenvolveram uma apresentação para a disciplina Química e outra para Estudos Regionais. Coube a cada professor atribuir um grau de acordo com o alcance dos objetivos e da proposta para os temas dentro de suas respectivas disciplinas.

A seguir, relacionaremos algumas das atividades propostas para cada um dos temas.

Tema 1: Desenvolvimento econômico e entorno da Baía de Guanabara.

- Listar as principais indústrias químicas do entorno da Baía, indicar seus principais produtos fabricados, seus principais efluentes e/ou resíduos sólidos gerados e os problemas 
ambientais causados ao ecossistema.

- Buscar as razões do modelo de industrialização de forma a entender o contexto atual. indústrias.

-llustrar com mapas a localização destas

-Produzir um texto que contasse a história de como a Região Metropolitana do Rio de Janeiro veio a se consolidar como importante centro urbano-industrial do Brasil.

Tema 2: Balneabilidade e qualidade das águas.

-Recuperar a natureza histórica do lazer na Região Metropolitana do Rio de Janeiro.

-Entender a relação entre os poluentes e a saúde humana.

-Explicar a importância da qualidade das águas para a biodiversidade da Baía. Pesquisar os parâmetros físico-químicos indicativos da qualidade das águas determinados pelos órgãos ambientais e como são monitorados.

-Pesquisar sobre os tipos de tratamentos físicos, biológicos e físico-químicos utilizados nas estações de tratamento de efluentes domésticos e industriais.

Tema 3: Atividade pesqueira.

-Analisar as transformações pelas quais passa a atividade desde a década de 1960.

- Ilustrar com mapas a localização das principais áreas pesqueiras, dos tipos de pescados e dos principais frigoríficos e áreas de comercialização de pescados no entorno da Baía de Guanabara.

-Produzir um texto contando a histórica importância da atividade pesqueira na subsistência de famílias e para a sustentação das atividades econômicas extrativas no entorno da Baía de Guanabara.

\section{-Comparar a pescar artesanal com a pesca "industrial".}

-Relacionar o desmatamento e aterramento de manguezais com a queda na produtividade pesqueira.

-Explicar o fenômeno da bioacumulação e as consequências da ingestão de frutos do mar contaminados por metais pesados como o mercúrio, o cádmio e o zinco.
Tema 4 : Lixo urbano e reciclagem.

- llustrar com mapas a localização das principais áreas de descarte de lixo urbano e industrial do entorno da Baía de Guanabara, diferenciando os lixões dos aterros sanitários e dos aterros controlados.

-Produzir um texto relatando o conflito entre as diferentes municipalidades quando o assunto é a destinação do lixo doméstico, industrial e hospitalar.

-Relatar iniciativas da sociedade civil, ONG's (organizações não-governamentais), governos, redes de solidariedade social e projetos ambientais que reflitam a questão da reciclagem de lixo.

-Relacionar o crescimento anual no volume de lixo ao modelo de desenvolvimento urbano e social centrado no consumismo.

-Fazer uma descrição dos processos usados para reciclar e reutilizar vidro, papel, metais, plásticos e pneus.

Tema 5: Transportes.

- llustrar mapas com a localização da área portuária e das principais ligações marítimas entre as diversas estações de barcas presentes no entorno da baía.

-Produzir um texto relatando os diversos casos de vazamentos e acidentes ambientais envolvendo estaleiros, derramamento de óleo de barcos e navios, além de acidentes ambientais com vazamentos químicos a partir dos rios que deságuam na baía.

-Pesquisar quais são os principais produtos químicos transportados por navios na baía e seus riscos para o meio ambiente.

\section{Quarto Bimestre}

O trabalho de campo foi o segundo momento no processo ensino-aprendizagem, que correspondeu à etapa em que os alunos puderam desvelar o imediatismo do aspecto paisagístico e abordar, de forma mais abstrata e contextualizada historicamente, a realidade visualizável por eles.

A atividade de visitação a área(s) afetada(s) pela degradação ambiental provocada pela atividade humana estimula o educando a refletir sobre a realidade mais imediata. A paisagem constitui-se como elemento de constatação. Ela denuncia a forma como a nossa 
sociedade urbano-industrial e capitalista relaciona-se e gere seus recursos ambientais. No entanto, ultrapassar o domínio do imediatismo fornecido pela constatação visual torna-se uma das tarefas mais importantes, quando se pretende desenvolver um trabalho de educação ambiental e sensibilização às questões ambientais junto aos educandos. Parafraseando Paulo Freire, 0 ato de educar envolve diretamente $\mathrm{o}$ ato de educar-se. Educador $\mathrm{e}$ Educando no movimento dialético do processo ensino-aprendizagem.

A Ilha do Fundão, localizada na Baia de Guanabara foi escolhida como área de visitação para o trabalho de campo. Nesta llha fica localizado o campus principal da Universidade Federal do Rio de Janeiro (UFRJ).

Os educandos tiveram que apresentar um relatório em grupo onde se buscou avaliar seu grau de maturidade frente à abordagem de uma temática que envolve seu cotidiano. Tivemos, nesta etapa, a importante e decisiva colaboração de duas graduandas do curso de geografia da UFRJ para nos auxiliar na tarefa de observação dos fenômenos ambientais no local escolhido por nós para a realização do trabalho de campo - a Ilha do Fundão. Foram selecionados vários pontos de observação neste local e em cada um destes elucidaram-se elementos problematizados durante os seminários realizados no terceiro bimestre. Consideramos este momento como o ápice e concretização das discussões e reflexões iniciadas no terceiro bimestre.

Outro momento importante foi o depoimento in loci da presidente da associação de moradores de uma comunidade existente no campus da UFRJ. Vários pontos foram destacados e os educandos demonstraram interesse na questão da segurança, do acesso, da relação entre a UFRJ e a comunidade e a visão estarrecedora da degradação ambiental observada na porção sul da llha do Fundão. A posteriori, os educandos visitaram as instalações de uma cooperativa de reciclagem de lixo, localizada na comunidade supracitada e lá puderam ter a dimensão do impacto sócioambiental da implementação de projetos sociais desse porte na geração de emprego, renda e os aspectos positivos de médio e longo prazos sobre o meio ambiente.

\section{O Blog como Proposta de Mediação Didática}

De forma a orientar as atividades de pesquisa e buscas na Internet, criou-se um blog (http://www.pbg2007.blogspot.com). Para além da função de meio, o blog (Figura1) cumpre o papel de aproximação, de ciberespaço de encontro, espaço de divulgação da produção escolar, da montagem de acervos escolares e de links de referência para reunir informações e promover a divulgação dos arquivos elaborados pelos alunos.

\section{Resultados}

$\mathrm{Na}$ primeira etapa do projeto, realizada durante 0 terceiro bimestre, os alunos se envolveram de forma satisfatória nas atividades propostas através da participação ativa nos seminários temáticos. Os grupos se encarregaram de levantar informações relevantes sobre os temas propostos e discutidos coletivamente. Houve uma percepção positiva por parte dos alunos, que afirmavam ter desenvolvido algo diferente daquilo que fazem usualmente no espaço escolar. Disseram que apesar das dificuldades enfrentadas na coleta, organização e exposição dos dados levantados, gostaram das atividades, pois realizaram uma pesquisa cujo escopo estava na relação entre disciplinas diferentes. Segundo o relato de um dos alunos "Gostamos das atividades. Somos cobrados em provas de vestibulares e exames sobre assuntos que envolvem conhecimentos de mais de uma disciplina. Isso não era o que costumávamos fazer. Nos seminários precisamos fazer isso".

A maioria dos alunos participou ativamente na discussão das questões propostas e houve um movimento intenso de interação dos alunos com os temas dos seminários de outros grupos. Estes buscavam contribuir com seus colegas, realizando indagações. Além disso, referiram ter compreendido a importância de conhecer os conceitos das disciplinas de Química e Estudos Regionais para entender as modificações de que ocorrem no ambiente físico e social em decorrência da interferência da ação humana. Ao discorrerem, por exemplo, sobre a questão da qualidade das águas, os alunos trouxeram para as discussões conceitos como os de concentração das soluções, solubilidade, acidez e basicidade, oxidação e redução, desenvolvimento industrial da região metropolitana do Rio de Janeiro e saneamento urbano.

$\mathrm{Na}$ segunda etapa, que foi realizada durante o quarto bimestre, tivemos impressões 
bastante positivas dos alunos diante do fato de estarem vivenciando uma pesquisa de campo, algo que thes pareceu positivo e pouco usual na prática pedagógica cotidiana realizada no espaço escolar. Conforme um aluno nos relatou:

-"a excursão fez com que pudéssemos ver na prática coisas que havíamos discutido durante os seminários. As coisas estavam ali na nossa frente: a poluição ambiental, as fábricas, o ar poluído" disse um aluno.

Outro aluno relatou suas impressões sobre a visita à cooperativa de reciclagem de lixo na Cidade Universitária;

-"Achei incrível aquelas pessoas simples que, através do lixo, tinham a esperança nos olhos. Eles nos receberam muito bem. Os catadores faziam questão de mostrar o que faziam. Eles tinham muito orgulho do que fazem (...). Foi algo muito vivo, pois visitamos uma vila de pessoas pobres e vimos o outro lado da moeda".

\section{Conclusões}

O ensino médio encontra-se numa importante encruzilhada de dilemas didáticopedagógicos e políticos. A pressão do vestibular, o currículo engessado em função dos conteúdos mínimos impostos pelo vestibular e o desempenho nas provas do ENEM (Exame Nacional do Ensino Médio), cujo ranking representa seu mais moderno símbolo etc., tudo isso conspiram contra as tentativas de se realizarem projetos que ultrapassem os limites e muros impostos pelas disciplinas escolares. Embora haja a proposta de questões integrativas de conteúdos na prova do ENEM, observamos o completo despreparo de uma geração inteira de professores para lidar com esses novos desafios, seja pela questão da formação nas licenciaturas no âmbito universitário, ou ainda, nos cronogramas escolares, na falta de um projeto político-pedagógico que integre os esforços mais corriqueiros do "chão da escola".

Outro exercício, não menos importante e um tanto difícil, foi o de convencer o jovem educando da relevância dessa proposta. Mostrávamos a eles 0 papel do diálogo interdisciplinar, a atual exigência em questões do vestibular, de modo que ocorresse uma aproximação da linguagem e angústias deles, mas acima de tudo, o papel social representado pela produção de conhecimentos no âmbito da escola. E essa experiência foi única, pois oportunizou aos educandos levantarem dados e informações sobre problemas concretos do seu cotidiano. Com isso, ultrapassou-se o mero utilitarismo do exame vestibular, a partir do qual a relevância do conteúdo se dá a partir de sua presença em provas desse processo seletivo.

A escolha da Baía de Guanabara como área de integração para nossos esforços analíticos foi outro ponto importante. Elemento paisagístico e regional importante no cotidiano dos alunos, esta não foi retratada apenas como mero palco das ações humanas, mas como elemento integrante da dinâmica socioeconômica da qual o educando também faz parte. Trazer elementos de críticas e sugestões para o grave problema ambiental que assola este importante subsistema ambiental que é a Baía de Guanabara, constitui-se num processo imprescindível na formação do jovem técnico em Administração de Empresas. $O$ suporte de conhecimentos da Química, aliados aos do processo de formação socioespacial, proporcionados pelos Estudos Regionais, já se coloca como um esforço importante de contato entre conceitos e categorias da Química e da aplicabilidade dos métodos de regionalização de espaços econômicos locais e supra locais, sua descrição histórica, seus modelos econômicos e concepções filosóficas e políticas. $E$, na educação ambiental, o pressuposto básico é exatamente este. Neste sentido, pode-se dizer que o objetivo principal foi atingido: o de fazer emergir o campo ambiental como espaço de diálogo e encontro de saberes/fazeres que são gestados em diversas disciplinas e, acima de tudo, no processo de escolhas políticas ditadas pela economia-mundo capitalista contemporânea, conduzindo o educando a um processo de crítica-ação.

\section{Referências}

1. BRASIL. Constituição da República Federativa do Brasil, 1988.

2. Ministério da Educação. Secretaria de Educação Média e Tecnológica. Parâmetros curriculares nacionais:ensino médio. Brasília, 1999.

3. DIAS, G. F. . Educação Ambiental, princípios e práticas. São Paulo: Gaia, 1992. 
4. GONÇALVES, C. V.. Os (des) caminhos do meio ambiente. São Paulo: Contexto, 1998.

5. GUIMARÃES, M.. A dimensão ambiental na educação. Campinas: Papirus, 1995.

6. LOUREIRO, C. F. B.. Educar, participar e transformar em educação ambiental. Revista brasileira de educação ambiental, Brasília, v. 0, n. 0, p. 13-20, 2004.
7. MACHADO, A. H. e MORTIMER, E. F.. Química para o Ensino Médio: Fundamentos, Pressupostos e o Fazer Cotidiano. In: ZANON, L. B., MALDANER, O. A. (Org.). Fundamentos e propostas de ensino de química para a educação básica no Brasil. ljuí: Ed. Unijuí, 2007.

8. VAITSMAN, E. P. e VAITSMAN, D. S.. Química \& meio ambiente: ensino contextualizado. Rio de Janeiro: Interciência: 2006.

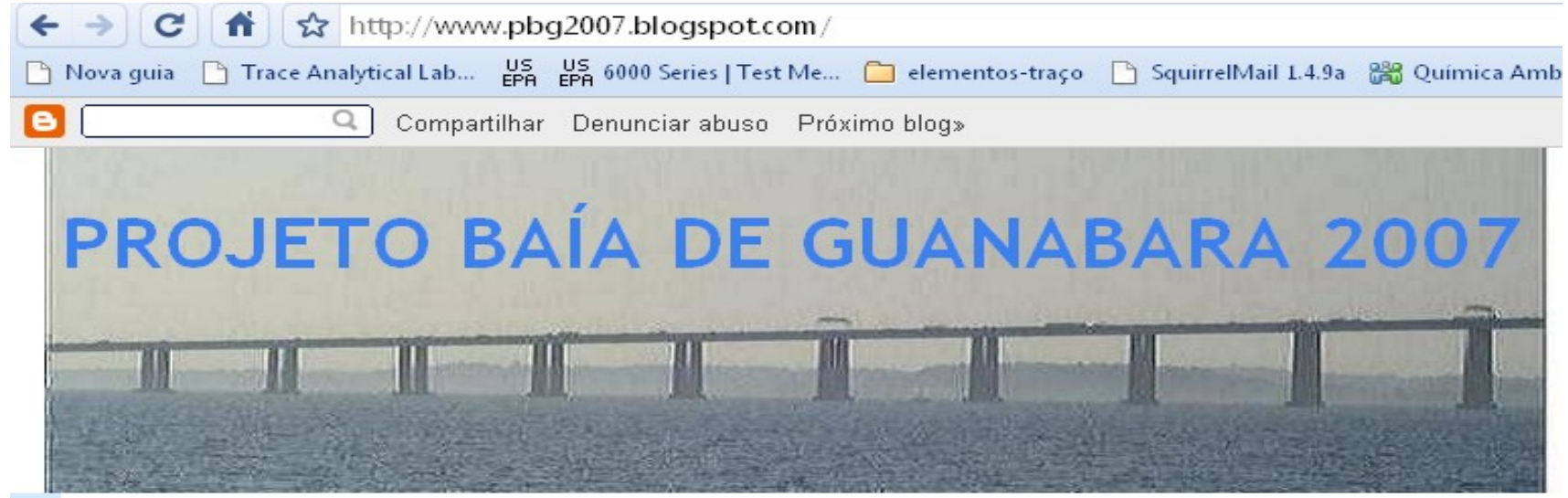

MAPINHA DO TRABALHO DE CAMPO

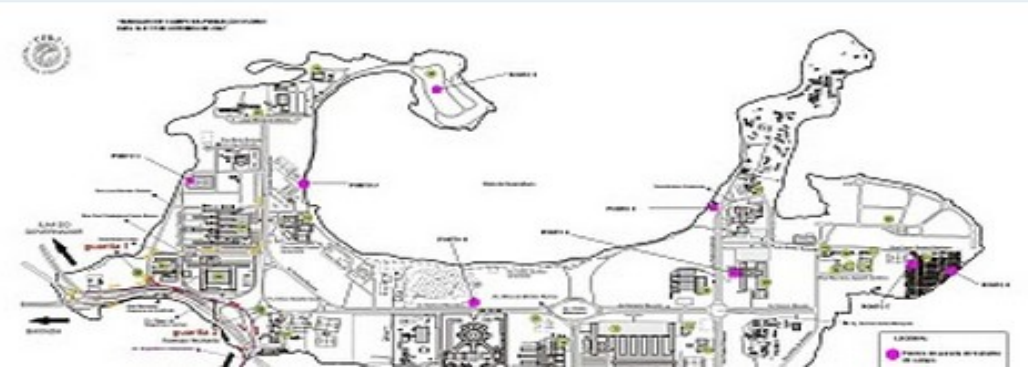

Figura 1 - Fragmento do blog utilizado no projeto. 